\title{
Rice Vision for Bangladesh: 2050 and Beyond
}

\author{
M S Kabir ${ }^{1}$, M U Salam² ${ }^{*}$ A Chowdhury ${ }^{1}$, N M F Rahman ${ }^{1}, K^{2}$ M Iftekharuddaula1, \\ M S Rahman'1, M H Rashid1, S S Dipti ${ }^{1}$, A Islam¹, M A Latif ${ }^{1}$, A K M S Islam¹, \\ M M Hossain ${ }^{1}$, B Nessa ${ }^{1}$, T H Ansari ${ }^{1}$, M A Ali ${ }^{1}$ and J K Biswas ${ }^{1}$
}

\begin{abstract}
Combined efforts of farmers, rice scientists, extension personnel and Government of Bangladesh have yielded clean rice growth rate of 0.34 million ton (MT) year-1 during 2009-10 to 2013-14 in the country. In 2014-15, the country acquired a rice surplus of about 2 MT. However, maintaining the current surplus of rice in the coming decades is a great challenge. Authentic estimation of future rice requirement and future resource availability would guide to way forward. This paper presents rice vision for Bangladesh leading to 2050 and beyond. In this study, secondary data from different government-owned statistics and research institutes were collected, analyzed and synthesized to develop models and/or model parameters to generate outputs such as future population, rice production and rice requirement. Population of Bangladesh will reach 215.4 million in 2050, when 44.6 MT of clean rice will be required. With the pace of rice-production-increase in the last five years, production can reach 47.2 MT, having a surplus of 2.6 MT in 2050. The study sets 2.6 MT as the target for clean rice surplus every year leading to 2050 and beyond. Several hurdles, such as increasing population, decreasing resources and increasing climate vulnerability, can hinder achieving the target. Three major interventions-accelerating genetic gain, minimizing yield gap and curtailing adoption lag-are proposed to break the barriers to achieve the target. Major challenges to implement the interventions include shrinking net cropped area, decreasing availability of irrigation water and increasing pressure on soil fertility. Smart technology such as, location specific variety, profitable cropping sequences, innovative cultural management, and mechanization coupled with smart dissemination using multiple means would ease production barriers. We recommend a number of measures, such as, guaranteeing a minimum cropped area, accelerating the rate of genetic gain in varietal development and intensifying collaboration among the stakeholders to reduce adoption lag of newly released promising rice varieties, to achieve the rice vision of Bangladesh leading to 2050 and beyond.
\end{abstract}

Keywords: Adoption lag, Bangladesh, cropping intensity, genetic gain, pest and diseases, population, mechanization, rice requirement and rice production

\section{INTRODUCTION}

Bangladesh agriculture involves food production for 163.65 million people from merely 8.75 million hectares of agricultural land (Salam et al., 2014). More food will be required in future because of increasing population. Decreasing resources (e.g. land, labour, soil health and water), and increasing climate vulnerability (e.g., drought, salinity, flood, heat and cold) appeared as the great challenges to keep the pace of food production in the background of increasing population. Sufficient rice production is the key to ensure food security in Bangladesh. In fact, 'Rice security' is synonymous to 'Food security' in Bangladesh as in many other rice growing countries (Brolley, 2015). Rice security is not just an economic issue but also an important parameter for determining social and political stability (Nath, 2015).
Since independence, there has been a three-fold increase in rice production in Bangladesh, which jumped from nearly 11 MT in 1971-72 to about 34.86 MT in 2014-15 (AIS, 2016). This has transformed the country from so called "Bottomless Basket" to a "Full of Food Basket". In recent years, the country has not only earned self-sufficiency in rice production, but also gradually entering into the export regime (BER, 2015). LaFranchi (2015) rightly said, "Bangladesh has emerged as a global model for combating hunger and obtained great success in becoming a country of food surplus from a country lagged with chronic food shortages". 
Combined efforts of farmers, rice scientists, extension personnel and Government of Bangladesh have enabled the country with a surplus of about 2 MT of rice in 2014-15. In the last few years (2009-10 to 2013-14), rice production has increased by $0.34 \mathrm{MT}$ per year (BBS, 2014). The challenge, however, is to continue maintaining the current surplus of rice in the coming decades in order to sustain rice security in the country. Before searching the way forward, it is needed to quantify the future rice demand and requirement, and address the resource utilization obligations. Bearing these in mind, this paper aimed to formulate a guideline to ensure sustainable rice production in Bangladesh up to 2050 and beyond.

\section{METHODOLOGY}

\section{Definition of terms}

Adoption lag. Time difference between releasing a rice variety and it reaches to the adoption peak, expressed as year.

Critical net cropped area. The minimum net cropped area as a function of national averaged clean rice yield to meet the projected rice requirement.

Cropping intensity. Cropping intensity, expressed as percentage, is the ratio of total cropped area and net cropped area in a particular year.

Rice. Rice denotes in this study for "clean rice" (or "milled rice") calculated as paddy rice $\times 0.65$ (Islam et al., 2006).

Net cropped area. Net cropped area is the maximum physical area cultivated in a year.

Smart technology. A technology which is sustainable, meets expectation and has business potential.

Yield gap. Difference between potential farm yield and actual farm yield.

\section{Data collection}

Secondary data (both published and unpublished) sourced from different government-owned statistics and research institutes were collected, analyzed and synthesized to develop model parameters and/or models for population prediction, rice production and requirement, rate of production increase of rice, adoption lag of varieties developed by the Bangladesh Rice Research Institute (BRRI), yield gap, cropping intensity, net cropped area, and soil organic matter (SOM) and rice yield relationship.

\section{Population prediction}

The model "ProjectPopBD" was developed and used to estimate population of Bangladesh from 1973 to 2100 , considering 66.4 million as the base population in the year 1972 (UNPD, 2015). The population of a given year " $x$ " can be calculated from the following equation:

Pop_Yr(x) $=$ Pop_Yr(x-1) + AddedPop_Yr(x) Eq. (1)

Here (in Eq. 1), Pop_Yr(x) is population (expressed as million) in the year " $x$ ", Pop_Yr(x-1) is population in the immediate past year and Added Pop_Yr(x) is the added population for the year " $x$ ". Added Pop_Yr(x) was calculated in two steps: one, by regressing five-year's average of observed population during 1972 to 2015 (Fig. 1).

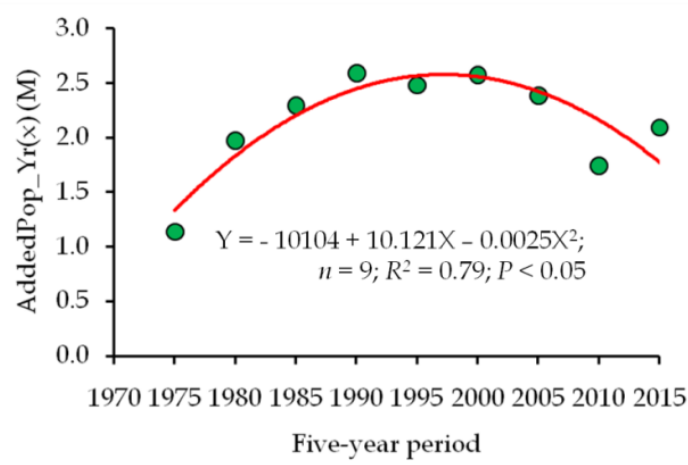

Fig.1. Estimated statistics of AddedPop_Yr $(x)$ in a fiveyear interval during 1970 to 2015. This statistics indicates the annual population to be added to the previous year's population in projecting current year's population (Eq. 1).

Secondly, multiplying immediate pervious AddedPop_Yr(x) by slider multipliers (MF_to_AddedPop_Yr(x)). The sliding multipliers were assumed based on future implication on population growth due to changing socio-economic factors of the country, such as better education, employment, women empowerment, rural development, financial capability, changes in social perception, and 
motivation and awareness. The values of AddedPop_Yr(x) used in Eq. 1 to estimate population of Bangladesh from 1972 through to 2100 are shown in Table 1.

Table 1. The value of AddedPop_Yr(x) and multiplication factor to AddedPop_Yr $(x)$ (MF_to_AddedPop_Yr $(x)$ ).

\begin{tabular}{|c|c|c|}
\hline Period & $M F \_t o \_A d d e d P o p \_Y r(x)$ & $\begin{array}{c}\text { AddedPop_Yr }(x) \\
\left(\mathrm{M}^{*}\right)\end{array}$ \\
\hline 1975 & - & 1.33 \\
\hline 1980 & - & 1.83 \\
\hline 1985 & - & 2.20 \\
\hline 1990 & - & 2.45 \\
\hline 1995 & - & 2.57 \\
\hline 2000 & - & 2.56 \\
\hline 2005 & - & 2.42 \\
\hline 2010 & - & 2.16 \\
\hline 2015 & - & 1.77 \\
\hline 2020 & 0.01 & 1.76 \\
\hline 2025 & 0.02 & 1.72 \\
\hline 2030 & 0.03 & 1.67 \\
\hline 2035 & 0.04 & 1.60 \\
\hline 2040 & 0.05 & 1.52 \\
\hline 2045 & 0.06 & 1.43 \\
\hline 2050 & 0.07 & 1.33 \\
\hline 2055 & 0.08 & 1.22 \\
\hline 2060 & 0.17 & 1.02 \\
\hline 2065 & 0.19 & 0.82 \\
\hline 2070 & 0.21 & 0.65 \\
\hline 2075 & 0.23 & 0.50 \\
\hline 2080 & 0.25 & 0.38 \\
\hline 2085 & 0.31 & 0.26 \\
\hline 2090 & 0.33 & 0.17 \\
\hline 2095 & 0.35 & 0.11 \\
\hline 2100 & 0.37 & 0.07 \\
\hline
\end{tabular}

\section{Requirement and production of clean rice}

The model "CleanRiceReq" was developed and used to calculate yearly requirement of clean rice in Bangladesh as a function of population as follows:

ReqClnRiceYr $(\mathrm{x})=$ Pop_Yr $(\mathrm{x}) \times$ MF_ReqCln Rice Eq. (2)

Here (in Eq. 2), ReqClnRiceYr(x) is the total requirement of clean rice, expressed as million ton (MT), in year " $\mathrm{x}$ ", Pop_Yr(x) is population in year " $x$ " (see Eq. 1), and MF_ReqClnRice is a constant.

Requirement of clean rice in Bangladesh has two components, the first one is for human consumption which is most often being confused as total requirement, and the second one is non-consumption uses. Per capita rice consumption in this country has been decreasing day by day. It was $179.9 \mathrm{~kg}$ person $^{-1}$ year $^{-1}$ in 1977 (Ahmad and Hasan, 1983), expected to decline to $147.2 \mathrm{~kg}$ person ${ }^{-1}$ year $^{-1}$ in 2020, and reach the threshold of $133.2 \mathrm{~kg}$ person $^{-1}$ year-1 $^{-1}$ in 2040 (Fig. 2).

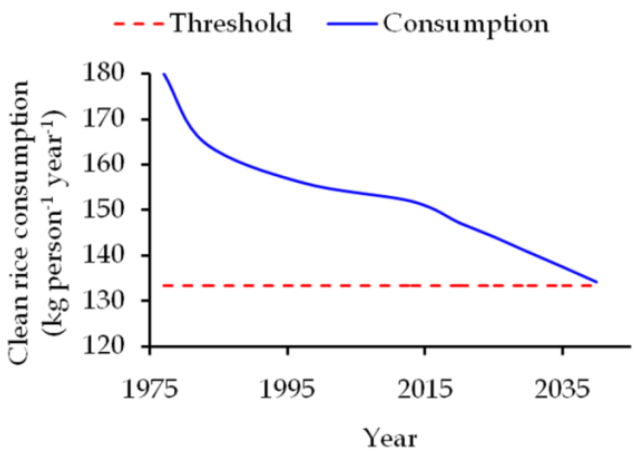

Fig. 2. The trend in declining clean rice consumption in Bangladesh (vertical line). The horizontal line shows the threshold, which is the absolute daily minimum intake of carbohydrate required to meet calorie from rice.

This threshold is the absolute daily minimum intake of carbohydrate required to meet calorie from rice (Murshid et al., 2008). In addition to human consumption, rice is required as seed and feed. Besides, a significant amount of production gets wastage in the field and/or during processing. The non-human consumption portion of rice adds about $25 \%$ of the production (FAO, 2011). We calculated the ratio of total rice requirements and population for the years 1972 to 2014, where the value of the ratio was almost the same (0.21) from 2008 onwards. We assumed this value for the constant MF_ReqClnRice (Eq. 2). Clean rice requirement estimated in this model was also designated as the "target requirement" of rice in future.

The developed model "CleanRicePdn" calculates annual production of clean rice according to the following regression equation:

$$
\operatorname{PdnClnRiceYr}(x)=a+b \times \operatorname{Yr}(x) \ldots . . . E q . ~(3)
$$

Here (in Eq. 3), PdnClnRiceYr(x) is the total production of clean rice, expressed as million ton (MT), in year " $x$ ", and " $a$ " and " $b$ " are 
parameters. Rice production data during 2010 to 2014 (BBS, 2015) were used to derive the parameter values (Fig. 3). In this study, production of clean rice estimated by the model is designated as the "target production" of rice for the future.

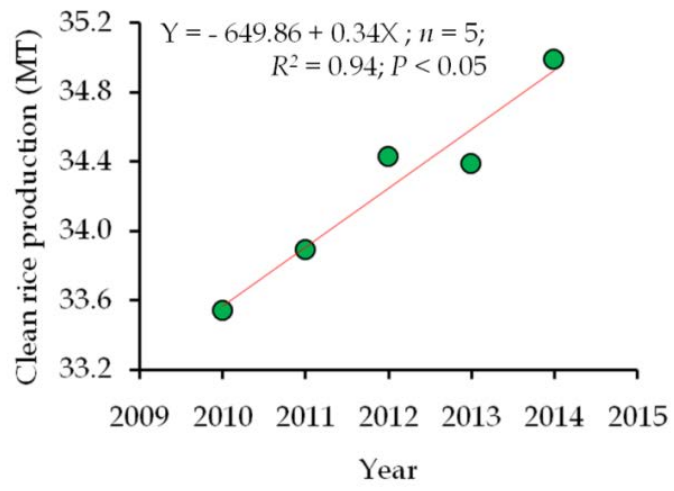

Fig. 3. The regression (solid straight line) between observed production (filled circle) of clean rice and corresponding year of production in Bangladesh

\section{Clean rice production under resource limitations}

In the present study, two factors were considered that could adversely affect future rice production in Bangladesh, (i) gradual decrease in rice land, and (ii) stagnation of national rice yield. These factors were accounted for in the following equation.

PdnClnRiceYr $(\mathrm{x}) \_W S=$ RiceLandYr $(\mathrm{x}-1) \times$ $((100-$ RLRR $) / 100) \times$ SNRY Eq. $(4)$

Here (in Eq. 4), PdnClnRiceYr(x)_WS is the production of clean rice (MT) under resource limitations in year " $x$ ", RiceLand $Y r(x-1)$ is land under rice ( $\mathrm{M}$ ha) in the immediate past year, RLRR is rice land reduction rate (\%) year- ${ }^{-1}$, and SNRY is stagnant national rice yield $\left(t \mathrm{ha}^{-1}\right)$. The RLRR is a constant and its value was taken as 0.4\% (The daily Prothom Alo, 2015). The SNRY is also a constant and the value ( $\left.3.17 \mathrm{t} \mathrm{ha}^{-1}\right)$ was derived from weighted average of national yield of Aus, T. Aman and Boro during 20092013 (BBS, 2015).

Interventions. Three interventions were employed in order to maintain the current momentum of rice production in Bangladesh. These are: (i) accelerating genetic gain, (ii) minimizing yield gap, and (iii) curtailing adoption lag of rice varieties in the field.

(i) Accelerating genetic gain. Clean rice production, by accounting for accelerating genetic gain, (PdnClnRiceYr(x)_Interven(1), MT) was calculated from the following equation.

PdnClnRiceYr(x)_Interven(1) RiceLand $\operatorname{rr}(\mathrm{x}) \times(\mathrm{CRYYr}(\mathrm{x}-1)+\mathrm{RYAC}) \quad$ Eq. (5)

Here (in Eq. 5), RiceLand $\operatorname{Yr}(x)$ is the rice land available for the year " $x$ " (M ha), CRYYr(x$1)$ is the clean rice yield $\left(t^{h a-1}\right)$ in the immediate past year, and RYAC is the rate of annual yield increase due to accelerating genetic gain ( $t \mathrm{tha}^{-1}$ year $\left.{ }^{-1}\right)$. The model was run with the base yield of $3.17 \mathrm{t} \mathrm{ha}^{-1}$ (the weighted average yield of Aus, T. Aman and Boro during 2009-2013).

(ii) Minimizing yield gap. Yield gap, as defined earlier, was calculated as a difference between potential farm yield and actual farm yield. The actual farm yield was calculated as a value of constant SNRY, described earlier in Eq. 4. The potential farm yield was calculated from the performance of five prominent BRRI varieties: BRRI dhan26 and BRRI dhan48 (Aus season), BRRI dhan49 (T. Aman season) and BRRI dhan28 and BRRI dhan29 (Boro season) (BRRI, $2015 b)$. The rough rice yiels was converted into clean rice yields by multiplying the factor or 0.65 (Islam et al., 2006), and compiled as weighted average. The calculated yield gap is presented in Fig. 4.

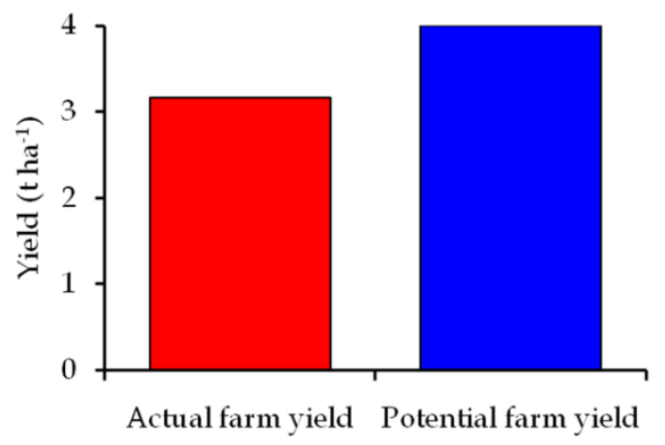

Fig. 4. The actual farm yield and potential farm yield of clean rice in Bangladesh, showing the yield gap of $0.83 \mathrm{tha}^{-1}$ or $20.7 \%$ 
Clean rice production, by accounting for minimizing yield gap,

(PdnClnRiceYr(x)_Interven(2), MT) was calculated from the following equation.

PdnClnRiceYr(x)_Interven(2) = RiceLandYr(x) $\times$ $(\mathrm{CRYYr}(\mathrm{x}-1)+\mathrm{CRYYr}(\mathrm{x}-1) \times \mathrm{YGRF}) \quad$ Eq. (6)

Here (in Eq. 6), YGRF is the annual yield gap reduction factor, a parameter of the model. The value of the parameter was calculated as 0.012 by using "solver" function in MS Excel 2010 by imposing a condition that the clean rice surplus in 2050 will remain at least as of the current figure.

(iii) Reducing adoption lag. Data of adoption of four prominent BRRI released varieties - BR11, BR22, BRRI dhan28 and BRRI dhan29 - in three seasons (Aus, T Aman and Boro) were gathered from the Agricultural Economics Division of BRRI. Data were fitted using three parameter Weibull equation (Jansen, 1992; Abernathy, 2006) to develop adoption curves (Fig. 5). The timing of accelerating genetic gain (Intervention 1) scenario was advanced by 5 and 10 years to mimic the reduction in adoption lag.

The outputs of the model run for the abovementioned three interventions were expressed as deficit or surplus of clean rice requirement compared to "target requirement". The "target requirement" is the amount of clean rice (MT) needed to maintain the expected surplus in 2050.

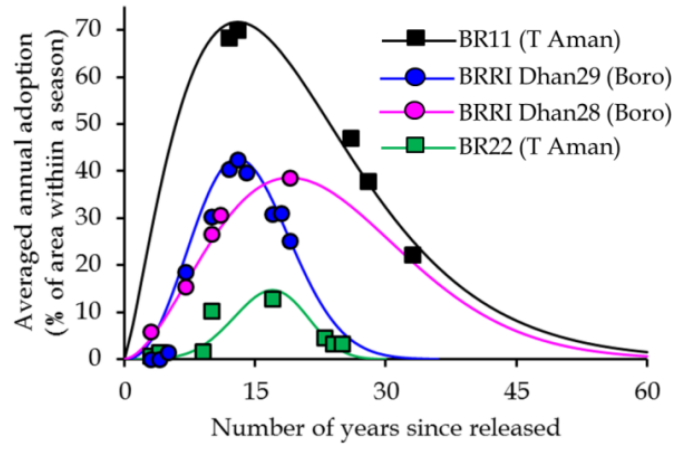

Fig. 5. The adoption curve of four prominent BRRI (Bangladesh Rice Research Institute) released rice varieties in three seasons in Bangladesh. The curves were fitted using three parameters Weibull equations using data from Agricultural Economics Division of BRRI

\section{Resource utilization obligations}

Net cropped area, critical net cropped area and rice area. Relationship between net cropped area and rice area was estimated through regression analysis. For this, 38 years' simulated data (2013 - 2050) were used. These data were generated from present study. Thereafter, a relationship between national average clean rice yield and critical net cropped area was established. The critical net cropped area, as defined earlier, is the minimum net cropped area as a function of national average clean rice yield to meet the predicted rice requirement.

Accumulation of soil organic matter. Accumulation of soil organic matter (SOM) in a Rice-Rice system was predicted from the following equation.

$$
\begin{aligned}
& \text { SOMYr }(x)=\operatorname{SOMYr}(x-1)+\text { SOMIR } \\
& \text { Eq. (7) }
\end{aligned}
$$

Here (in Eq. 7), SOMYr(x) is the SOM (\%) in year " $x$ ", SOMYr(x-1) is the SOM in previous year and SOMIR is the annual increase of SOM. The value of SOMIR was calculated as $0.009 \%$ from 22 years experimental data from BRRI's research station at headquarters, Gazipur.

Prediction of cropping intensity. The ratio of net area sown to the total cropped area or cropping intensity of Bangladesh was calculated based on the net cropped area (NCA), single cropped area (SCA), double cropped area (DCA) and triple cropped area (TCA) of Bangladesh recorded in the Year Book of Agricultural Statistics for different years (1992-2013). The historical data (1972 to 2012) and its trend were used to simulate the long term cropping intensity of Bangladesh. Based on the previous trends, it was considered that SCA would be decreasing gradually for the initiatives of adopting new crops in different stress environment and would reach to $1,789,000$ ha in 2037 with the present trend of technological advancement. We further assumed that the SCA would be reduced @ 2\% from 2037 on due to adoption of third generation stress tolerant varieties of crops. The model considers the TCA would be increasing 
@ 44,000 ha year-1 up to $2,277,000$ ha in 2026 onwards, but a part of that would be shifted to four cropped area through the adoption of super short duration crops. The DCA would be decreasing due to shifting DCA to the TCA. The limit of decreasing SCA and increment of TCA up to a certain limit was calculated consulting the database of Elahi et al. (2001) and the dataset of Bangladesh Bureau of Statistics for different years.

\section{RESULTS AND DISCUSSION}

\section{Population of Bangladesh: 2050 and beyond}

In 2015, population of Bangladesh stood at 160.0 million. Our model predicts the population in 2030 will be 186.0 million, which will reach to 215.4 million in 2050. As shown in Fig. 6, we further predict that the population of this country will become almost static around the year 2071 (about 243 million). In the end of this century, the population of Bangladesh is predicted to reach 249.3 million.

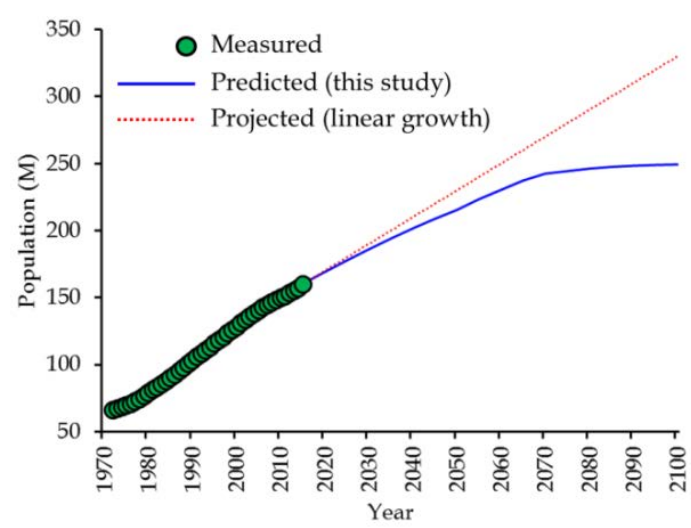

Fig. 6. Measured (solid filled circles from 1972 to 2013) and predicted (solid exponential line) population of Bangladesh leading to 2100. The broken line shows the projected population if the growth continued to be linear.

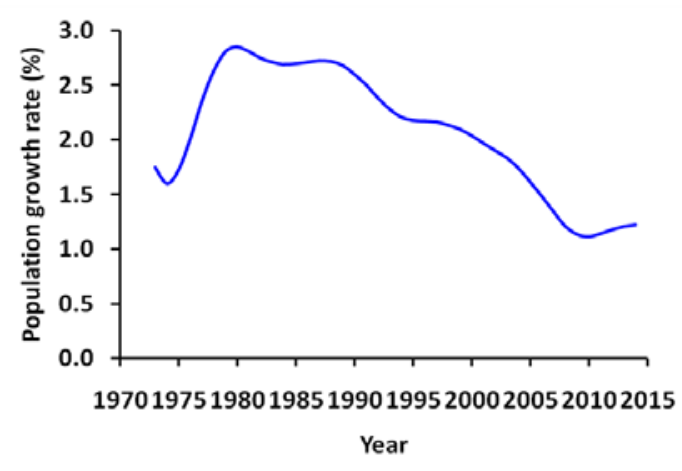

Fig. 7. Population growth rate in Bangladesh during 1972 to 2015 (prepared by authors, data from UNDP (2015)).

From yearly population data of Bangladesh (Fig. 7), it is evident that the population growth rate was higher in late 70 's (UNPD, 2015). Growth rate is decreasing since 1980 (2.85\%) and currently (2014) stands as $1.22 \%$. Considering medium fertility as variant, United Nations Population Division (UNPD) has anticipated that there will be an added population of more than 56 million by 2050 to share the total available food (Mukherjee et al., 2011).

It may be noted that the Government of Peoples' Republic of Bangladesh has proclaimed "Vision 2021" to drive the country's sustainable development agenda by striking the right balance between equitable national economic progress and human development (MOP, 2015). In predicting the population, incremental effect of various Government interventions were considered. For example, the scope for better education, wider employment facilities, women empowerment, rural development, financial solvency, changes in social perception, and motivation and awareness. It is obvious to expect that increased investment, faster human capital accumulation, enhanced productivity growth and higher outward orientation will lead the country toward becoming middle income and/or developed country within 2050. Government's planning for "Vision 2021" incorporates cent percent net enrolment at primary school, reducing unemployment rate to $15 \%$, reducing maternal mortality to $1.5 \%$, raising the use of birth control methods to $80 \%$, bringing down 
infant mortality to 15 per thousand live births, ensuring minimum intake of 2,122 kcal person ${ }^{-1}$ day $^{-1}$ and standard food for $85 \%$ of the population (MOP, 2015). Although Bangladesh retains one of the highest proportions of teenage marriage in the world (Streatfield and Karar, 2008), it is experiencing a trend of gradual delay in age of marriage for young women. Substantial investments on educational inputs like free schooling for girls up to grade 12, national female secondary school stipend scheme along with improved scope of employment in Ready-made Garment (RMG) sector are being translated into delayed marriage. Continued government interventions in female education and empowerment would bring changes in livelihoods and social perceptions in the coming decades resulting delays in marriage and contribute in decreasing number of child per woman. Rural population growth rate is a big force that elevates the total population. Rapid urbanization has been turning "rural" Bangladesh into "city-like" Bangladesh which has a negative impact on family development. In the coming decades, there will be a provision of social security and allowances for the common people that would guarantee better financial capability. The social perception of the rural population of the country is changing. People in the country no longer believe that older-aged generation will be looked after by the family members, thereby no need to increase family member for this purpose. Better medical facilities, health insurance, living assistance and allowances, and communication and information technology will uplift mass people's living standard and way of thinking. Moreover, awareness of development programs taken by public and private organizations will negatively influence population growth.

\section{Clean rice requirement and production}

Bangladesh needs to feed 215.4 million people in 2050. The current consumption of rice is 148 $\mathrm{kg}$ person $^{-1}$ year $^{-1}$, which is decreasing by 0.7 percent each year. This trend is expected to lead the requirement to the threshold level of $133 \mathrm{~kg}$ person $^{-1}$ year- $^{-1}$ by 2040 (Fig. 2). Furthermore, around $25 \%$ of the production is required for non-consumption uses like seed, feed, wastage, and processing (FAO, 2011). Considering those, our model (Eq. 2) accurately predicted clean rice requirement in Bangladesh during 19722013 (R2 = 0.98; $\mathrm{n}=42 ; \mathrm{P}<0.05$, Fig. 8). The partitioning of clean rice requirement between consumption and non-consumption during 1972-2014 is shown in Fig. 9. The figure indicates that during 2014 the total requirement of clean rice was 32.8 MT (24.1 MT for consumption and 8.7 MT for non-consumption). During the same period, the country produced 34.86 MT of clean rice, indicating a surplus of 2.06 MT. We set the rice vision for Bangladesh for 2050 and beyond to maintain, at least, this surplus.

Rice production in Bangladesh has taken significant momentum since 1990-91, especially during two phases, from 1996-97 to 2000-01 and from 2009-10 to 2013-14 (Fig. 10). Significant reasons for this include, Government's support in mechanization and irrigation, controlling fuel and fertilizer price hike, improved loan distribution policy (loan deposit directly to farmers' account operated with 10 Taka only), well organized fertilizer supply, increased quality seed supply by public and private sectors, and technological interventions (e.g. genetic improvements for favorable and unfavorable ecosystems).

With the current rate of production increase by $0.34 \mathrm{MT}$ year-1 $^{-1}$ (averaged during 2010-14), rice production in 2050 could reach to $47.2 \mathrm{MT}$, given the area under rice remains unchanged. Our model predicts, the clean rice requirement for the country in 2050 would be 44.6 MT resulting a surplus of 2.6 MT (Fig. 11). 


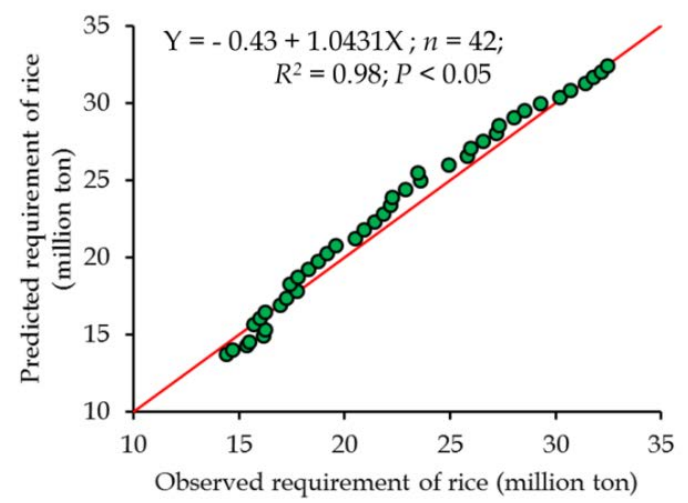

Fig. 8. Regression between observed (filled circles) and predicted requirement of clean rice during 2072 to 2014 . The solid line indicates 1:1 line passing through origin.

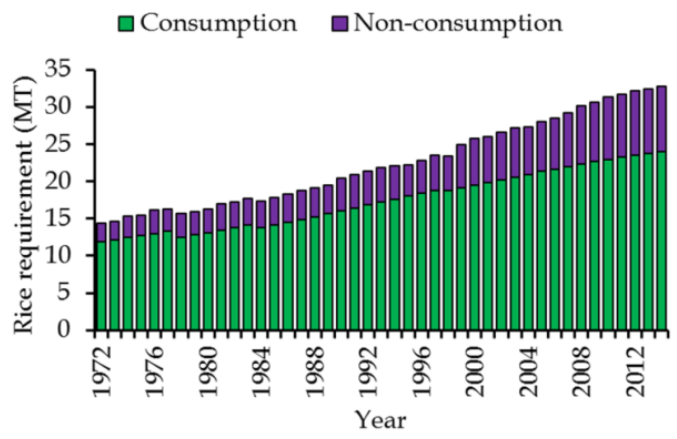

Fig. 9. Partitioning of clean rice requirement in Bangladesh between consumption and nonconsumption purposes during 1972-2014.

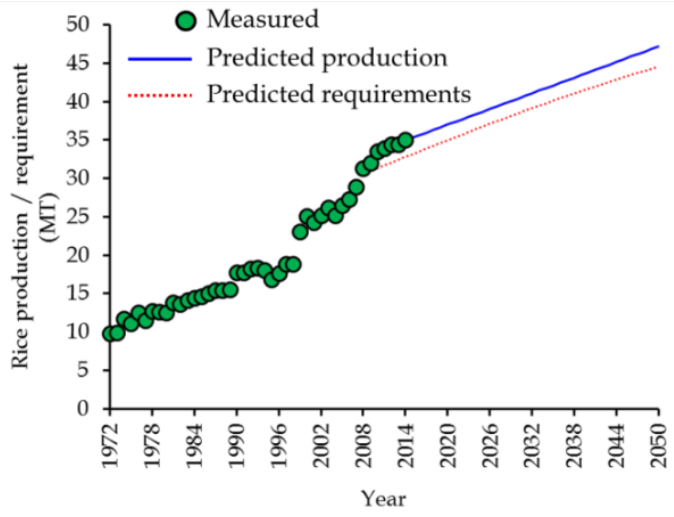

Fig.10. Phasic development, averaging five-year period, of clean rice production in Bangladesh during 1990-91 to 2013-14. Vertical bars indicate standard errors.

\section{Portraying future scenario of rice production under resource limitations}

There is a hind side of the predicted clean rice production leading to 2050 as depicted above. Statistics indicate that the area under rice has been decreasing at the rate of $0.4 \%$ year $^{-1}$

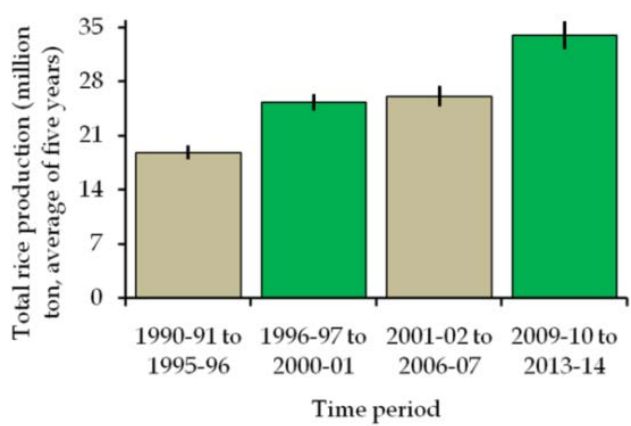

Fig. 11. Measured (filled circles, from 1972 to 2014) and projected requirement and production of clean rice in Bangladesh leading to 2050.

(The daily Prothom Alo, 2015). If the trend continues and the current national rice yield remains unchanged (average of $3.17 \mathrm{t} \mathrm{ha}^{-1)}$, we predict 31.1 MT clean rice production in 2050 from 9.8 $\mathrm{M}$ ha rice area (Fig. 12). This translates as a production deficit of 16.1 MT and requirement deficit of $13.5 \mathrm{MT}$ in 2050 to what we calculated in Fig. 11.

\section{Interventions for achieving rice production goal for 2050}

The challenge would be to lift the future rice production of Bangladesh from the "red" line to "blue" line in Fig. 12 in order to achieve the goal of maintaining at least 2.6 MT surpluses in 2050. Three major interventions were employed to achieve the goal.

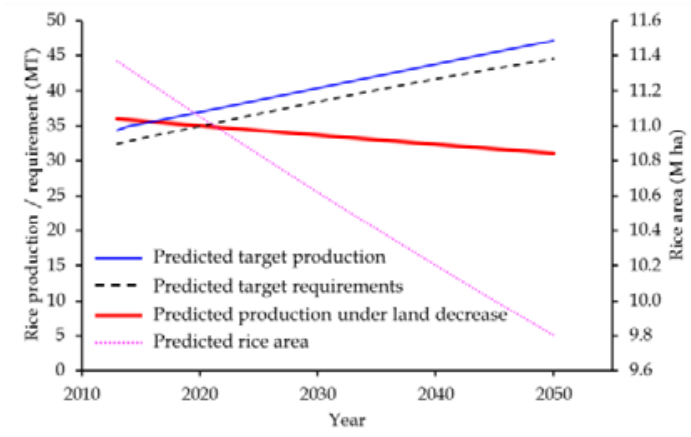

Fig. 12. Predicted decrease in rice area and consequent clean rice production, target production and requirement of clean rice leading to 2050. The target production aims to ensure rice surplus of at least 2.6 MT in the year 2050. 
Intervention 1. Results show that by incrementally improving genetic yield potential of rice by $0.044 \mathrm{t} \mathrm{ha}^{-1}$ year-1, it is possible to

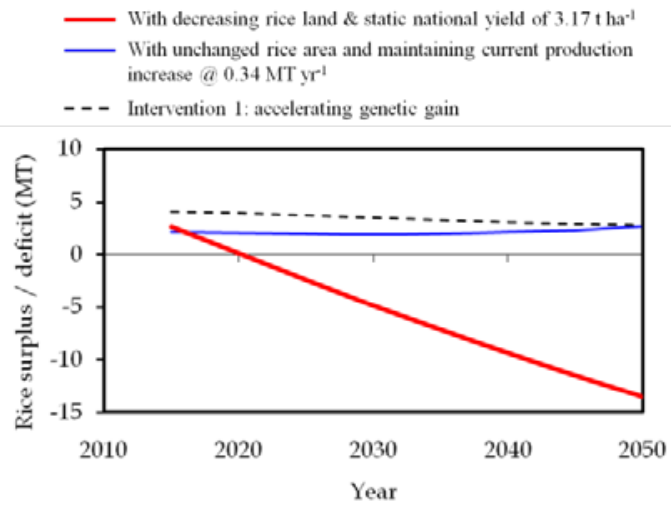

Fig. 13. Achieving clean rice surplus of at least 2.6 MT in year 2050 through the intervention of accelerating genetic gain @ $0.044 \mathrm{t} \mathrm{ha}^{-1}$ year $^{-1}$.

secure 2.7 MT of surplus in 2050 (Fig. 13). If this is to happen, the current national average clean rice yield of $3.17 \mathrm{t} \mathrm{ha}^{-1}$ will have to be elevated to $4.82 \mathrm{t} \mathrm{ha}^{-1}$ in 2050 .

Intervention 2. We calculated the yield gap of $0.83 \mathrm{t} \mathrm{ha}^{-1}$ (or 20.7\%) between actual farm yield and potential farm yield in Bangladesh (Fig. 4). If this yield gap could be reduced @ 1.135\% year-1, 4.8 MT surplus in 2050 (Fig. 14) can be achieved.

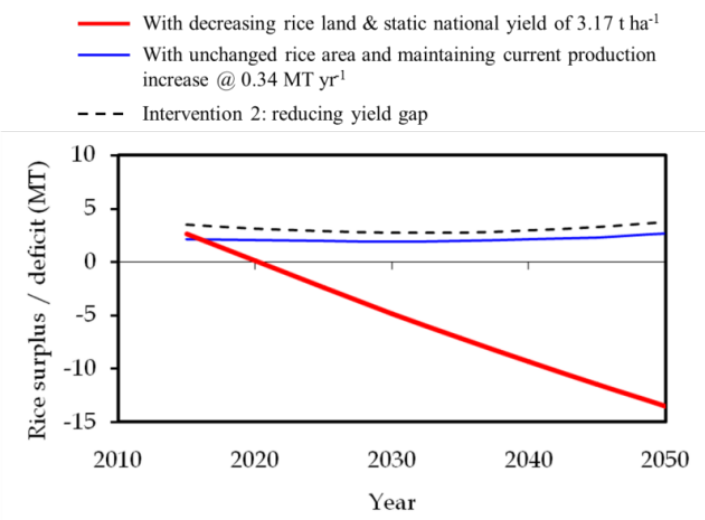

Fig. 14. Achieving clean rice surplus of at least 2.6 MT in year 2050 through the intervention of reducing yield gap @ $1.135 \%$ year $^{-1}$.

Intervention 3. The average time to reach the adoption peak of BRRI (Bangladesh Rice Research Institute) released promising varieties has been calculated as $16 \pm 3$ years (Fig. 5). Results show that curtailing this adoption lag of newly released promising varieties by 5 years and 10 years will result in clean rice surplus of 2.1 MT and 4.3 MT, respectively, in 2050 (Fig. 15).

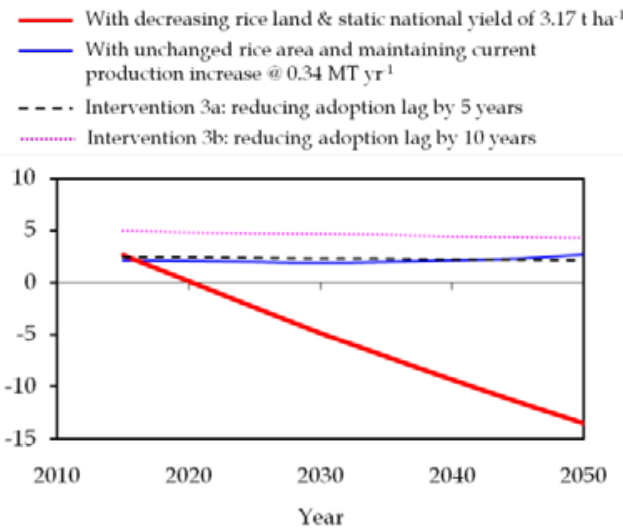

Fig. 15. Achieving clean rice surplus of at least 2.6 MT and 4.6 MT in year 2050 through the intervention of curtailing adoption lag of newly released promising varieties by 5 years and 10 years, respectively.

\section{Resource utilization obligations}

For implementing the above mentioned interventions, there would be several obligations to utilize the resources. Land is the key factor for crop production and shrinking cultivable land area is the major threat for the agriculture sector of Bangladesh. The available crop land is under immense pressure of providing food for the big population. Moreover, imbalanced fertilization and increased cropping intensity is hampering soil health. We have pointed out some obligations that would address whether the country's rice land is being affected or not with the decrease of net cropped area, how much land should critically be guaranteed for rice cultivation in the coming decades and how intensively we are allowed to deplete our soil.

Our analysis found a strong positive relationship between net cropped area and rice area in Bangladesh (Fig. 16). This indicates that any change in net cropped area will equally affect rice area, thereby likely to influence the rice production. 


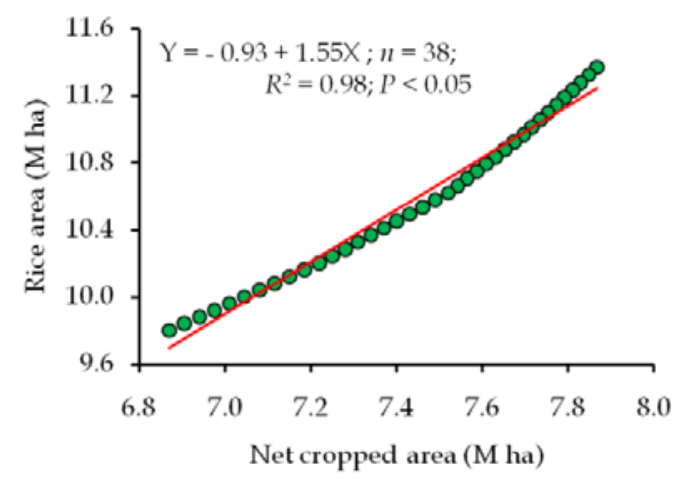

Fig. 16. Regression between net cropped area and rice area during 2013 to 2050 . Solid line is the linear regression and filled circles are the estimations.

The minimum net cropped area to meet the rice requirements leading to 2050 will depend on achievable national yield. Fig. 17 shows that provided farmers' yield reach at 4.5, 5.0 and 6.0 $\mathrm{t} \mathrm{ha}^{-1}$, respectively, a minimum of $6.98,6.29$ and $5.71 \mathrm{M}$ ha of net cropped area to be guaranteed to meet national rice requirement in 2050.

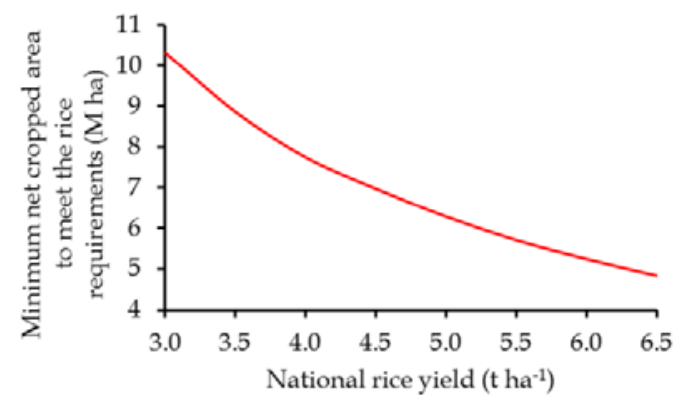

Fig. 17. Relationship between achievable national clean rice yield and the minimum net cropped area to meet the clean rice requirement in 2050.

Soil organic matter is a key to maintain soil health. BRRI (Bangladesh Rice Research Institute) research data shows about $2.4 \%$ of soil organic matter is critical to achieve annual rice yield of above $10 \mathrm{t} \mathrm{ha}^{-1}$ (Fig. 18). Research findings further indicate that in the Rice-Rice cropping systems, soil organic matter content does not deteriorate, rather it increases. It has been estimated that maintaining $20 \mathrm{~cm}$ rice straw cut height can eventually elevate soil organic matter content to threshold level of $2.4 \%$ (Fig. 19) and add $30-40 \mathrm{~kg} \mathrm{ha}^{-1}$ muriate of potash (MOP) fertilizer in the soil (BRRI, 2015a).

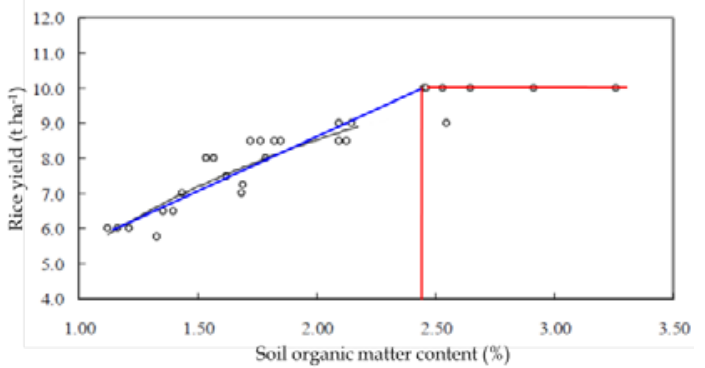

Fig. 18. Critical soil organic matter (SOM) content to maintain high rough rice yield $\left(>10 \mathrm{t} \mathrm{ha}^{-1}\right)$. Data from various agro-ecological zones of Bangladesh. Reconstructed from published figure presented in the Annual Research Review 2009-10, Soil Science Division, Bangladesh Rice Research Institute (BRRI). Blue line shows increase of yield with increasing SOM, and the horizontal red line shows static yield when the SOM reaches $\sim 2.4 \%$ (vertical read line).

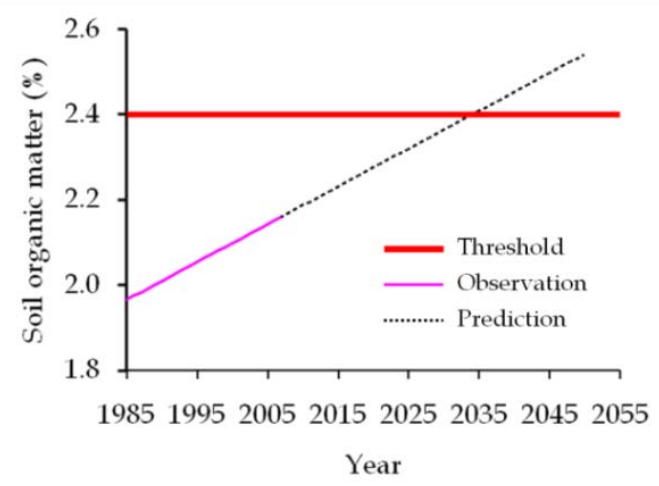

Fig. 19. Observed and predicted soil organic matter content in the rice-rice cropping systems through maintaining $20 \mathrm{~cm}$ rice straw cut height. The threshold indicates the level to be ensured to achieve annual rough rice yield of above $10 \mathrm{tha}^{-1}$.

Long-term BRRI research indicates that rice productivity can be increased any time by refertilization of zero-fertilized rice land. Figure 20 shows re-fertilization of zero-fertilized rice land after 14 years restored productivity as of fertilized land. Therefore, proper management of soil for getting the highest yield is an urgent need. 


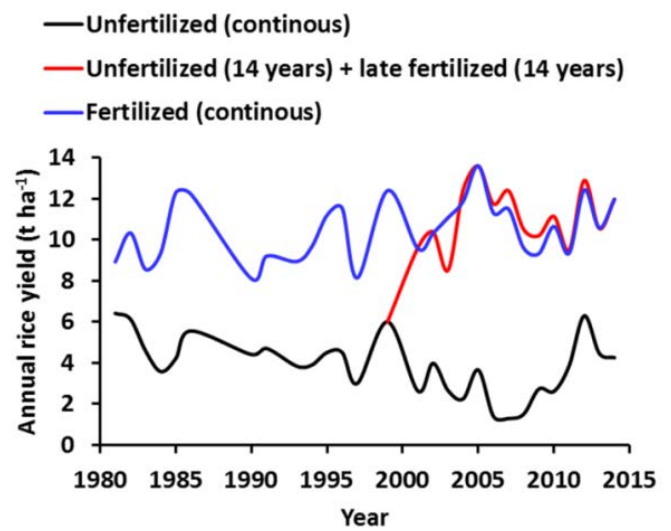

Fig. 20. The long-term experimental results at BBRI research station headquarters at Gazipur, Bangladesh. Re-fertilization of zero fertilized rice land after 14 years restored productivity as of continued fertilized land.

It would be difficult to feed the growing population by practicing only organic agriculture in rice production. Use of balanced fertilizers (urea, triple superphosphate (TSP), muriate of potash (MOP), Zinc (Zn) and Sulfur (S)) is a necessary mean of exploring the yield potential of rice varieties. Balanced fertilization has no serious harmful effect on soil health for further crop production rather the production will decline under organic practice alone. However, application of rotten poultry litre @ 2 t ha ${ }^{-1}$ (on a dry-weight basis) can supply full amount of TSP and S for rice and save $50 \%$ of urea and MOP (BRRI, 2015a). Use of Urea Super Granule (USG) is another mean of urea management which is considered as resource saving and trigger the yield.

There will be limited scope of increase in cropping intensity, which stands as 193\% in 2015 (BBS, 2015). Our model predicts the cropping intensity of Bangladesh cannot be exceeded beyond $221 \%$ leading to 2050 (Fig. 21).

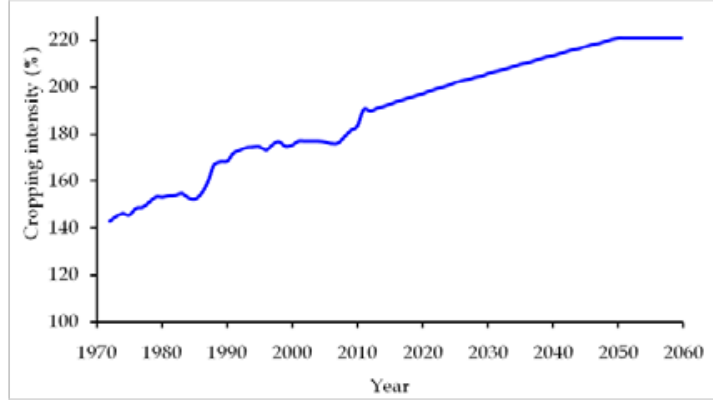

Fig. 21. Predicted cropping intensity of Bangladesh leading to 2050 and beyond
Declining ground water table is a common scenario across the agricultural regions of Bangladesh, where Boro rice is greatly affected. Obligations, in this regards, include, shifting of $\sim 15 \%$ "water shortage Boro area" to rainfed culture (i.e., Aus rice), adoption of dry-direct seeded aerobic culture, scoping partial irrigation for T. Aus during crop establishment and supplementary irrigation for T. Aman, finding and adopting short duration high yielding T. Aman rice varieties (Rabi (winter) crop in preceding season), and efficient utilization of water in rice cultivation.

Profitability is an essential driver to sustain rice production of Bangladesh. As a common nature, rice production can get reduced in the following year if the profitability of current year is not ensured. For this, farmers need to get right price for their products. Steps are required to formulate efficient rice marketing system involving all stakeholders so that farmers can receive profitable farm-gate price.

\section{Options to maintain the momentum: smart technology}

Improved variety. A number of smart rice varieties have been released by BRRI (Bangladesh Rice Research Institute) for different environments and seasons (Table 2). For example, in T. Aman season under favorable ecosystem, BRRI dhan62 has 100 days growth duration with $5.0 \mathrm{t} \mathrm{ha}^{-1}$ yield potential, BRRI dhan72 is zinc enriched (22.8 ppm) variety with 125-130 days growth duration and $5.5 \mathrm{t}$ ha1 yield potential, BRRI dahn49 is one-week earlier than BR11with Nizersail-type grain with $5.5 \mathrm{t} \mathrm{ha}^{-1}$ yield potential, BRRI dhan70 is a long slender aromatic variety with 130 days growth duration and $5.0 \mathrm{t} \mathrm{ha}^{-1}$ yield potential. For the same season, BRRI dhan66, BRRI dhan70, BRRI dhan71 and BRRI dhan72 could be replaceable to "Swarna" as these varieties possess similar yield potential with 10-25 days earlier growth duration than "Swarna" cultivars. During T. Aman, BRRI dhan56, BRRI dhan66 and BRRI dhan71 have drought tolerance, BRRI dhan52 has submergence tolerance, BRRI dhan41, BRRI dhan54 and BRRI dhan73 have salinity

Rice Vision for Bangladesh: 2050 and Beyond 11 
tolerance, BR22, BR23 and BRRI dhan46 are suitable for late planting under post-flood situation, BR23 and BRRI dhan30 can tolerate moderate water stagnation, and BRRI dhan44 can tolerate moderate tidal submergence.

Table 2. List of smart rice varieties released by the Bangladesh Rice Research Institute (BRRI) for different environments and seasons

\begin{tabular}{|c|c|c|}
\hline Category & Conventional variety & Smart variety \\
\hline \multicolumn{3}{|l|}{ T. Aman: Favourable environment } \\
\hline \multirow[t]{3}{*}{ Short duration } & BRRI dhan33 & BRRI dhan62 \\
\hline & BRRI dhan39 & BRRI dhan72 \\
\hline & & BRRI hybriddhan4 \\
\hline Medium/long duration & BR11 & BRRI dhan 49 \\
\hline Aromatic high yielding & BRRI dhan38 & BRRI dhan70 \\
\hline \multicolumn{3}{|l|}{ Possible replacement of "Swarna" in rainfed } \\
\hline \multirow[t]{4}{*}{ lowland } & Swarna & BRRI dhan66 \\
\hline & & BRRI dhan70 \\
\hline & & BRRI dhan71 \\
\hline & & BRRI dhan72 \\
\hline \multicolumn{3}{|l|}{ T. Aman: Unfavourable environment } \\
\hline \multirow[t]{3}{*}{ Drought } & - & BRRI dhan56 \\
\hline & & BRRI dhan66 \\
\hline & & BRRI dhan71 \\
\hline Submergence & - & BRRI dhan52 \\
\hline \multirow[t]{3}{*}{ Salinity } & - & BRRI dhan 41 \\
\hline & & BRRI dhan54 \\
\hline & & BRRI dhan73 \\
\hline \multirow[t]{3}{*}{ Late planting (post flood) } & - & BR22 \\
\hline & & BR23 \\
\hline & & BRRI dhan 46 \\
\hline \multirow[t]{2}{*}{ Water stagnation(moderate tolerance) } & - & BR23 \\
\hline & & BRRI dhan 30 \\
\hline Tidal submergence (moderate tolerance) & - & BRRI dhan 44 \\
\hline \multicolumn{3}{|l|}{ Boro: Favourable environment } \\
\hline \multirow[t]{2}{*}{ Short duration } & BRRI dhan28 & BRRI dhan60 \\
\hline & & BRRI dhan63 \\
\hline \multirow[t]{2}{*}{ Long duration } & BRRI dhan29 & BRRI dhan60 \\
\hline & & BRRI dhan63 \\
\hline \multirow[t]{2}{*}{ Premium quality } & - & BRRI dhan50 \\
\hline & & BRRI dhan63 \\
\hline High zinc & - & BRRI dhan74 \\
\hline Hybrid & - & BRRI hybriddhan3 \\
\hline \multicolumn{3}{|l|}{ Boro: Saline environment } \\
\hline Salt tolerant & BRRI dhan47 & BRRI dhan67 \\
\hline \multicolumn{3}{|l|}{ T. Aus: Favourable environment } \\
\hline Standard duration & Parija & BRRI dhan 48 \\
\hline & Jamaibabu & BRRI dhan65 (also as \\
\hline & BR26 & B. Aus) \\
\hline & & NERICA Mutant \\
\hline
\end{tabular}

In Boro season, BRRI dhan58 is 7-10 days earlier than widely adopted BRRI dhan29 with similar yield potential and grain quality, whereas, BRRI dhan60 has $\sim 1.0 \mathrm{t} \mathrm{ha}^{-1}$ yield advantage with extra-long slender grain and
3-4 days longer growth duration than another mega-variety BRRI dhan28. BRRI dhan50 and BRRI dhan63 are the export potential premium quality high yielding (6.0-7.0 $\mathrm{t}$ ha-1). BRRI dhan74 is a zinc enriched (24.2 ppm) variety, 
yielding ability of 7.1-8.3 $\mathrm{t} \mathrm{ha}^{-1}, 147$ days duration, $28 \%$ amylose content, moderately tolerant to blast disease; besides, BRRI dhan 67 which has slender grains is better tolerant to salinity compared to BRRI dhan 47 .

Disease management. Rice diseases always have a significant impact on rice productivity.In Bangladesh, a total of 32 rice diseases have been identified. Historically, severe epidemics led to serious food shortages due to diseases. The Bengal famine in 1942 was, in part, attributed to brown spot of rice disease (Padmanabhan, 1973). Bacterial leaf blight and neck blast are chronic diseases both in T. Aman and Boro season in Bangladesh while severity of sheath blight has been higher in T. Aman season. Bacterial leaf streak has become an emerging disease in both T. Aman and Boro season. Tungro and Root knot diseases are serious threat especially to Aus rice cultivation in Bangladesh. Regarding host resistance, it is unfortunate that resistance capacity of a particular disease resistant variety deteriorates or totally breaks down because of emerging a new race of the pathogen in few years. Understanding both pathogen population structure as well as host pathogen resistance is the prerequisite in designing of effective strategy for deployment of resistance. Durable resistant varieties can help to minimize the resistance breakdown problem. Gene pyramiding is one of the ways to develop durable resistant variety (Ashkani et al., 2015). New races of pathogen population of the diseases like blast and bacterial blight could be evolved causing threat to rice disease management. For example, recently BRRI dhan 28 is being affected seriously with leaf or neck blast although it had been considered as moderately resistant to blast since its release (BRRI 2015a). Identification of physiological races of bacterial blight and blast diseases are in progress (Khan et al., 2009; Khan et al., 2014) for the development of durable resistant varieties. However, the control of blast and sheath blight diseases can be done following integrated disease management strategies (BBRI, 2015b). Recently developed TSR (Tray
Seedling Raising) is highly effective protocol in raising healthy seedling against seedling blight disease (Ansari et al., 2016). TSR protocol will eliminate the adoption barrier of mechanical transplanter in Boro season. Another smart technology "Ankuri" can ensure healthy seed germination saving around $20 \%$ seed resource during cold environment (Ansari and Ahmed, 2015).

Rice false smut is a typical example of changing status of a disease in Bangladesh. This disease is now emerging, which is hindering adoption of a promising T. Aman rice variety, BRRI dhan49. Intensive research is underway to formulate prescription for the management of the disease. The yield loss model has been developed (Nessa et al., 2015a), and spatial distribution leading to an important aspect of the epidemiology of the disease under natural condition have been studied (Nessa et al., 2015b). While proper chemical control option has not been worked out yet, the disease likely to be managed through adopting a transplanting time so that the T. Aman rice does not flower on and after mid-October (Fig. 22). Late planting is also vulnerable to production of sclerotia (the resting stage of the pathogen), the inoculum source for next year's disease infection.

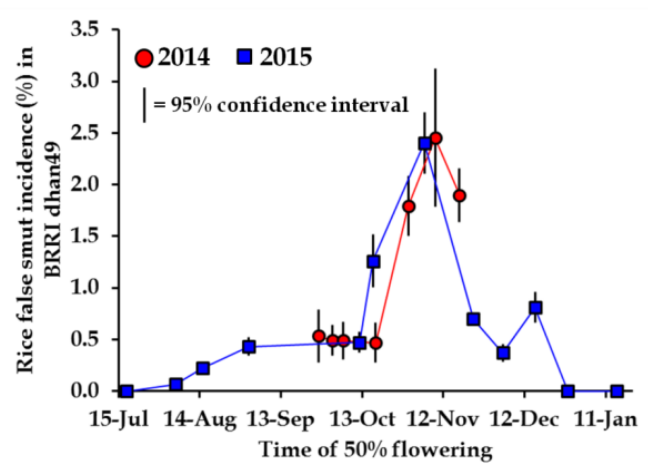

Fig. 22. Incidence of rice false smut disease on BRRI dhan 49 as affected by the flowering time of the crop (Nessa et al., 2015c)

Disease management systems, across the world, have relied primarily on new resistant varieties based on single gene, cultural management practices and on application of fungicides. A true measure of a successful disease research and management program is 
required to sustain modern agriculture with the needed intensity to meet food demand. In addition, monitoring and preparedness for preventive measures like gene pyramiding, durable resistant varieties and disease forecasting, sustainable integrated disease management and seed health management technologies should be taken into account.

Insect pests management. In the years leading to 2050, rice planthoppers ( $\mathrm{RPH}$, such as brown plant hoppers (BPH), whitebacked planthoppers (WBPH) and small brown Planthopper (SBPH)) as migratory pests, Leaf folder (LF), Gall-midge (GM), Mealy bug and Rice rats (for short duration varieties like BRRI dhan62) can become major damaging pests. Invading new pests like SBPH and Rice black beetle could evolve causing threat. Furthermore, some insects might change their biotype (e.g., BPH and GM) Therefore, preventive measures by strengthening surveillance and field monitoring system for pests (such as, using Light Trap and Yellow Sticky Trap) and environment friendly pest management options like perching, ecoengineering with pest and natural enemies, and establishment of Owl Watching Tower for rat control should be taken into account.

Human nutrition. Sustainable food security is not only depends on sustainable food production but also include the intake of food calories and nutrition. Commercial exploitation and efficient rice processing of nutrient enriched rice could be an attractive. Premium quality rice and zinc and iron enriched rice could be the planned target.

Parboiling reduces glycemic index (GI) value by 16 to $30 \%$ compared to the non-parboiled (Larsen et al., 2000). Reducing the degree of milling from 10 to 6 or $4 \%$ increase mean zinc content to 27 and $47 \%$, respectively (Dipti, 2013). Rice itself does not cause common lifestyle diseases (e.g. Alzheimer's disease, cancer, chronic liver disease/ cirrhosis, diabetes and heart disease).
Rice is a source of nutrition. Changes in food habit as well as rice based nutrient enriched food processing should be taken into consideration to achieve or accelerate the projected threshold rice intake at $133.2 \mathrm{~kg}$ person $^{-1}$ year-1 by 2050 or even before.

Mechanization. The agricultural labor force has followed decreasing trend $(48.3 \%$ in $2002-$ 03 and $45.1 \%$ in 2013) whereas increased in non-agricultural sector (51.7\% in 2002-03 and $54.9 \%$ in 2013) due to shifting from low productivity to high productivity sector (BBS, 2015). Transplanting, weeding, harvesting, threshing and cleaning are the most labor intensive operations in rice cultivation. Mechanical transplanting reduces $61 \%$ labor and $18 \%$ cost, weeder reduces $74 \%$ labor and $72 \%$ cost, and mechanical harvesting saves $96 \%$ labor and $72 \%$ cost compared to traditional method (Islam et al., 2016). In order to make agriculture attractive and sustainable to future generation, cent percent mechanization is essential for enhancing productivity. Such mechanization will allow timely and faster operation with less drudgery. It will minimize labor shortage, reduce postharvest loss by $2-3 \%$, and increase head rice recovery by 2-3\% (Islam, 2004).

Land reform (changing size and shape) and creation of farm road for accessibility of farm machinery are very important aspects to operate machines at full capacity. Government assistance is needed for purchasing high cost machinery especially transplanter and combine harvester. Much awareness programs need to be strengthened for successful farm mechanization. Service provider oriented mechanization could be an effective way for getting faster benefit. Land preparation by power tiller is such an example in this country being practiced in the last decades. Publicprivate partnership approach is another way to manufacture quality machine, develop skilled operator and mechanic and promote farm mechanization. Policy makers can consider this 'service provider mechanization system' and Government should come 
forward to equip the service provider with subsidized rice transplanter, reaper, and combine harvester. Commercial utilization of these agricultural machineries will definitely help for food security and sustainability in this country.

Ensuring quality seed supply. Considering a conservative estimates of seed multiplication rate (1:80), minimum of $80 \mathrm{~kg}$ "Foundation Seed" can be produced from one kg "Breeder Seed". From this $80 \mathrm{~kg}$ "Foundation Seed" and a minimum of $6400 \mathrm{~kg}$ "Certified Seed" can be produced. BRRI annually produces around 100 ton "Breeder Seed", from which 6.5 lakh ton "Certified Seed" can be produced. This amount is about double of the national quality seed demand.

However, $35 \%$ of the quality seed is now being supplied by the government. The rest of the seed sources are the farmers' saved rice seed produced for their own food, NGO's seed, private traders or local market. Those are not good quality seeds as a whole. Therefore, quality seed production and distribution system should be ensured so that quality seed become available and farmers can use good quality seed in rice production. This will ultimately minimize yield gap and significantly increase productivity.

\section{Options to maintain the momentum: smart dissemination}

A number of avenues are available or to be available to smartly disseminate smart technologies. These include, use of televisions, such as Bangladesh Television or BTV (Mati O Manush, Banglar Krishi, and Krishi Songbad), Channel i (Hridoye Mati O Manush, Manusher Dak, and Krishi Songbad), Bangla Vision (Shaymol Bangla), and Boishakhi Television (Krishi O Jibon), GTV (Shobuj Bangla); and radios, e.g. Bangladesh Betar (Desh Amar Mati Amar, Krishi Shomachar, Shonali Foshol, Shobuj Prantor, and Shoshho Shaymol). Other facilities could be the Agricultural Call Centre (cell number: 16123), BRRI Web Portal (www.brri.gov.bd), and
Bangladesh Rice Knowledge Bank (BRKB) and its mobile apps (www.knowledgebankbrri.org). Technologies could also be smartly disseminated through "Fact Sheets" and BRRI Newsletter. Social networks, such as, Krishi Bhabna and Krishi Kotha, could also be used for smartly dissemination of technologies. Application of GIS techniques is a good way of presenting a rice variety adoption domain as shown in Fig. 23.

\section{CONCLUSIONS AND RECOMMENDATIONS}

Clean rice surplus in Bangladesh is targeted as at least 2.6 MT in 2050 based on requirementproduction scenario. This target could be achieved through three major interventions accelerating genetic gain, minimizing yield gap and curtailing adoption lag. Several obligations have been identified to implement the interventions taking into account of limited net cropped area, limited cropping intensity, scarcity of water for irrigation and other purposes, immense pressure on soil fertility and productivity. Smart technology and smart dissemination can help overcoming production barriers.

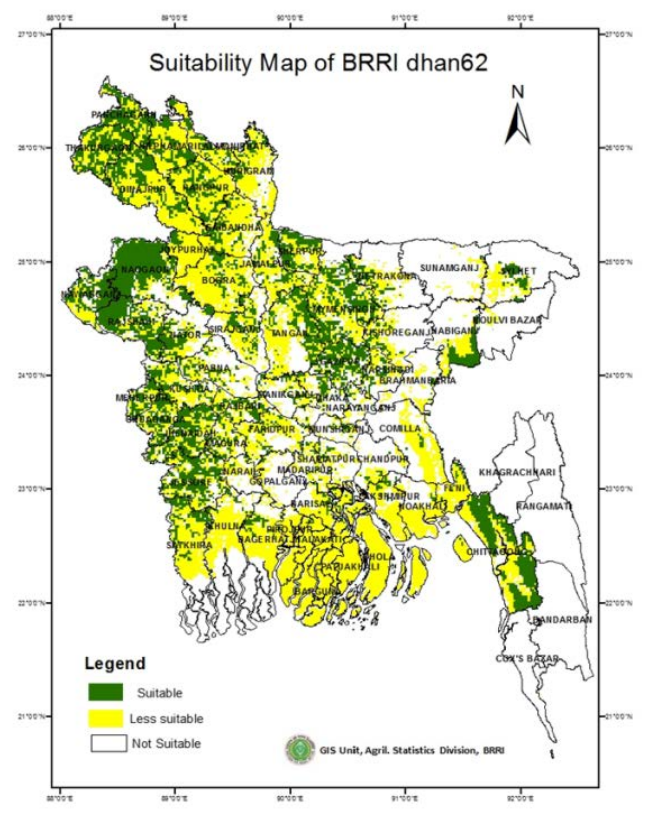

Fig. 23. Land suitability map for BRRI dhan62.

Rice Vision for Bangladesh: 2050 and Beyond 15 
Following recommendations are made from this study.

- Net cropped area to be guaranteed minimum of $6.29 \mathrm{M}$ ha in 2050, given the expected national clean rice yield of $5.0 \mathrm{t}$ ha $^{-1}$.

- Agricultural policy planning to be formulated by reminding that cropping intensity cannot be increased beyond $221 \%$.

- The rate of genetic gain in varietal development of BRRI's breeding program should be accelerated.

- Intense collaboration among the stakeholders is required to reduce adoption lag of newly released promising rice varieties.

- Variety and/or environment specific crop management systems should be formulated to reduce yield gap in farmers' field.

- Multiplication of BRRI produced $100 \mathrm{t}$ "Breeder Seed" would be needed annually to ensure quality seed supply to adequately meet national demand.

- Monitoring and forecasting of diseases, insects and pests infestation should be regulated to ensure proper management of the biotic hazards.

- At least $20 \mathrm{~cm}$ straw cut height to be ensured to maintain soil organic matter content to threshold level of $2.4 \%$.

- Hundred percent mechanization should be targeted in all stages of crop production.

- Conversion of engelberg huller to rubber rolls huller to increase head rice recovery.

- Encourage "pressure parboiling" to reduce glycemic index (GI) value of rice.

- Degree of milling should be reduced to increase inherent zinc content and other nutrition.

- Effort to be made on shifting of around $15 \%$ "water shortage Boro area" to rainfed culture, and accommodate dry-directseeded aerobic rice.

- Development of water-use-efficient varieties should be strengthened.

- Proper plan to be formulated for rainwater harvest and increased utilization of surface water (rubber dam, sluice gate, flash gate and dugwell).

- Scoping should be initiated for construction of desalinization plant(s), and re-excavation of canals and rivers.

- Arrangements to be made for skill development of farmers, extension workers and scientists through appropriate training.

- $\quad$ Rice price and farmers' profitability to be ensured.

- Efficient rice marketing system should be developed.

\section{ACKNOWLEDGEMENTS}

This article is based on the keynote paper to be presented in the 24th Rice Research and Extension Workshop at the Bangladesh Rice Research Institute (BRRI), Gazipur-1701 on 6th February 2016. The technical part of this study was led by the second author when he was on unpaid leave from the Department of Agriculture and Food, Western Australia (DAFWA) and working as an honorary scientist at the BRRI.

\section{REFERENCES}

Abernethy, D R B. 2006, The New Weibull Handbook (5th edition), Robert B. Abernethy publisher, North Palm Beach, Florida, USA.

Ahmad, K and N Hassan. 1983. Nutrition Survey of Rural Bangladesh, 1981-82. Institute of Nutrition and Food Science, University of Dhaka, Bangladesh.

AIS.2016. Krishi Diary 2016, Agricultural Information Service, Khamarbari, Farmgate, Dhaka-1215, Bangladesh.

Ansari, T H and M Ahmed. 2015. "Ankuri"- A climate resilient smart technology for rice seed germination and raising seedling in cold environment. Abstract no. 58. Proceeding of the 14th conference of Bangladesh Society of Agronomy, Bangladesh Rice Research Institute (BRRI), Gazipur-1701, Bangladesh.

Ansari, T H, M Ahmed and M A Ali. 2016. Control of seedling blight in raising healthy seedling of rice in tray. Proceeding of the 9th biennial conference of Bangladesh Phytopathological Society held at 19 February, 2016, Bangladesh Agricultural Research Institute (BARI), Gazipur-1701, Bangladesh.

Ashkani, S, M Y Rafii, M Shabanimofrad, A Ghasemzadeh, S A Ravanfar and M A Latif. 2015. Molecular progress on the mapping and cloning of functional genes for blast disease in rice (Oryza sativa L.): current status and future considerations. Crit. Rev. Biotechnol. 36 (2): 353-367.

BBS (Bangladesh Bureau of Statistics). 2014. Statistical Yearbook Bangladesh. Ministry of Planning, Government of the People's Republic of Bangladesh, Sher-E-Bangla Nagar, Bangladesh. 
BBS (Bangladesh Bureau of Statistics). 2015. Labour survey for Bangladesh 2013. Ministry of Planning, Government of the People's Republic of Bangladesh, Sher-E-Bangla Nagar, Bangladesh.

BER (Bangladesh Economic Review). 2015. Bangladesh Economic Review 2015. Ministry of Finance, Government of the People's Republic of Bangladesh, Bangladesh Secretariat, Bangladesh.

Brolley, M. 2015. Rice security is food security for much of the world. Rice Today. International Rice Research Institute (IRRI), DAPO Box 7777, Metro Manila, Philippines. PP. 30-32.

BRRI (Bangladesh Rice Research Institute). 2015a. Annual Report 2014-15. Bangladesh Rice Research Institute, Gazipur-1701, Bangladesh.

BRRI (Bangladesh Rice Research Institute). 2015b. Adhunik Dhaner Chash (Modern Rice Cultivation), 19th Edition. Bangladesh Rice Research Institute, Gazipur-1701, Bangladesh (in Bangla).

Dipti, S S. 2013, Effect of different degrees of milling on the retention of $\mathrm{Fe}$ and $\mathrm{Zn}$ in different rice varieties, BRRI Annual Report 2012-2013, Bangladesh Rice Research Institute, Gazipur1701, Bangladesh.

Elahi, N E, A H Khan, M R Siddique, A Saha, M Nasim, M I Mollah and S M Shahidullah. 2001. Existing cropping patterns of Bangladesh: potential technologies and strategies for improving systems productivity. Proc. of the workshop on Modern Rice Cultivation in Bangladesh. pp. 107-170.

FAO. 2011. Food Balance Sheet for Bangladesh, 2011. Food and Agriculture Organization of the United Nations. http://faostat3.fao.org/browse/FB/*/E (Accessed on 18 January 2016).

Islam, A K M S. 2004. Milling yield benefit from conversion of engelberg huller to rubber roll huller: A survey report. Submitted to the Farm Machinery and Postharvest Technology Division, Bangladesh Rice Research Institute (BRRI), Gazipur-1701, Bangladesh.

Islam, A K M S, M A Zaman, M P Islam and M Z A Vhutto. 2006. Study on coarse rice processing in a commercial Rice Mill. J. Agric. Mach. Bioresour. Eng. 4 (1\&2): 47-56.

Islam, A K M S, M T Islam, M S Rahman, M A Rahman and M A Kader. 2016. Selective mechanization in rice cultivation for enhancing productivity. Report published under IAPPBRRI fund, Farm machinery and Postharvest Technology Division, Bangladesh Rice Research Institute, Gazipur 1701, Bangladesh.

Jansen, H G P. 1992. Gini's coefficient of mean difference as a measure of adoption speed: theoretical issues and empirical evidence from India. Agril.Econ.7: 351-369.

Khan, M A I, M S Kabir, M A Monsur, M A Ali and M A T Mia. 2009. Pathogenic diversity of Xanthomonas oryzae pv. oryzae in Bangladesh. Bangladesh J. Plant Pathol. 25 (1\&2): 1-6.

Khan, M A I, M A Ali, M A Monsur, I Koga, K A Tanaka, N Hayashi, M Obara, M A T Mia and Y Fukuta. 2014. Population dynamics and pathotype evaluation of rice blast fungus (Pyricularia oryzae Cavara) in Bangladesh. The 4th International Rice Congress, October 27-31, 2014, Bangkok, Thailand.

LaFranchi, W. 2015. From famine to food basket: how Bangladesh became a model for reducing hunger. The Christian Science Monitor CSMonitor.com.

http://www.csmonitor.com/USA/ForeignPolicy/2015/0617/From-famine-to-foodbasket-how-Bangladesh-became-a-model-forreducing-hunger (Accessed on 12 December 2015).

Larsen, H N, OW Rasmussen, P H Rasmussen, K K Alstrup, S K Biswas, I Tetens, S H Thilste and K Hermansen. 2000. Glycaemic index of parboiled rice depends on the severity of processing: study in type 2 diabetic subjects. Euro. J. Clin. Nutr. 54: 380-385.

MOP (Ministry of Planning). 2015. 7th Five Year Plan 2016-2020. Ministry of Planning, Government of the People's Republic of Bangladesh. Sher-E-Bangla Nagar, Bangladesh http://www.plancomm.gov.bd/ wp-content/ uploads/2015/10/7th_FYP_18_02_ 2016.pdf. (Accessed on 18 December 2015).

Mukherjee, N, G A Chowdhury, M F A Khan and A K M Islam. 2011. Implication of Changing Consumption Pattern on Food Security and Water Resources in Bangladesh. Proceedings of the 3rd International Conference on Water and Flood Management (ICWFM 2011), 8-10 January 2011, Dhaka, Bangladesh, Vol. 2, pp. 731-738.

Murshid, K A S, M N I Khan, Q Shahabuddin, M Yunus, S Akhter and O H Chowdhury. 2008. Determination of food availability and consumption patterns and setting up of nutritional standard in Bangladesh. World Food Programme, UN Offices, IDB Bhaban, E/8 Rokeya Sharani Road, Agragaon, Sher-EBangla Nagar, Dhaka 1207, Bangladesh.76 pages.

Nath, N C. 2015. Food security in Bangladesh: Status, challenges and strategic policy options. Paper presented at 19th Biennial Conference of the Bangladesh Economic Association (BAE), held on 8-10 January, 2015, Dhaka, Bangladesh.

Nessa, B, M U Salam, A H M M Haque, J K Biswas, W J MacLeod, M A Ali, K P Halder and J 
Galloway. 2015a. FLYER: A simple yet robust model for estimating yield loss from rice false smut disease (Ustilaginoidea virens). Am. J. Agric. Biol. Sci.10 (1): 41-54.

Nessa, B, M U Salam, A H M M Haque, J K Biswas, M S Kabir, W J MacLeod, M D'Antuono, H N Barman, M A Latif and J Galloway. 2015b. Spatial pattern of natural spread of rice false smut (Ustilaginoidea virens) disease in fields. Am. J. Agric. Biol. Sci. 10: 63-73.

Nessa, B, M U Salam, A H M M Haque, J K Biswas, M A Latif, M A Ali, T H Ansari, M Ahmed, N Parvin, M Z Baki, S Islam, M S Islam and J Galloway. 2015c. Rice false smut disease at different flowering times. Bangladesh Rice J. 19(2): 29-35.

Salam, M U, S M A Hossain, J K Biswas and A J Mridha. 2014. Managing the unmanageable: rice variety technology for future challenging food security in Bangladesh. Extended abstract in the "Agronomic visions in challenging future", the proceedings of the 13thconference of the Bangladesh Society of Agronomy, 20 September 2014, Bangladesh Rice Research Institute (BRRI), Gazipur, Bangladesh.

Streatfield P K and Z A Karar. 2008. Population Challenges for Bangladesh in the Coming Decades. J. Health Popul. Nutr. 26 (3): 263-264.

Padmanabhan, S Y. 1973. The great Bengal famine. Annu. Rev. Phytopathol. 11:11-26.

The Daily Prothom Alo. 2015. Jomi komleo chal utpadon bereche tin goon (Rice production has increased by three times in spite of decreased land). http://prothomalo.com/bangladesh/article/ 658390, (Accessed on 18 October, 2015) (in Bangla).

UNPD (United Nations Population Division). 2015. United Nations Population Division of the United Nations. http://esa.un.unpd/wpp/download/ standard/ population.(Accessed on 18 December 2015). 